Egypt. J. of Appl. Sci., 35(12) 2020

$136-150$

\title{
THE COMBINED EFFECT OF MAITLAND SPINAL MOBILIZATION WITH MECHANICAL LUMBAR TRACTION IN PATIENTS WITH CHRONIC NON- SPECIFIC LOW BACK PAIN
}

\author{
Hamdy E. Mohamed ${ }^{1 *}$; Wadida H. Elsayed ${ }^{2}$ and Yasser M. Aneis ${ }^{2}$
}

${ }^{1}$ Physical therapist, ministry of health, Saqulta hospital, Sohag, Egypt.

${ }^{2}$ Professor of Physical Therapy for Basic science department, Faculty of Physical Therapy, Cairo University;

${ }^{3}$ Assistant Professor of Physical Therapy for Basic science department, Faculty of Physical Therapy, Cairo University.

* Corresponding author: Hamdy E. Mohamed

E-mail: drhamdy.elhawary.89@gmail.com

Key Words: Maitland spinal mobilization; lumbar mechanical traction; combined effect; nonspecific low back pain.

\section{ABSTRACT}

Background: Non-specific low back pain (NSLBP) is pain not attributed to a recognizable pathology, not attributable to a known cause, represents 90-95\% of the cases of LBP. Objectives: to investigate the combined effect of Maitland spinal mobilization and lumbar traction on pain intensity, range of motion (ROM), and functional disability in patients with chronic nonspecific low back pain. Design: A randomized controlled trial. Subjects and Methods: Forty-four subjects with chronic nonspecific low back pain participated in this study, their ages ranged from 20 to 30 years. Participants were randomly subdivided into four equal groups (each consist of 11 patient and received 3sessions per week for 4 weeks): Group (A): received central posterior-anterior mobilization in addition to conventional physical therapy and advices. Group (B): received intermittent mechanical lumbar traction in addition to conventional physical therapy and advices. Group (C): received intermittent mechanical lumbar traction with central posterior-anterior mobilization in addition to conventional physical therapy and advices.

Group (D) (Control group): received conventional physical therapy (Transcutaneous electrical nerve stimulation, Infrared, and Isometric exercise) and advices. outcome measures: Pain intensity assessed by visual analogue scale (VAS), lumbar ROM assessed by Bubble Inclinometer, and functional disability assessed by the Arabic version of modified Oswestry disability questionnaire (MODQ). All outcomes were taken pre and post treatment. Results: Multiple comparison analysis showed a potential difference between groups in terms of the selected parameters, while the major changes favored group $\mathrm{C}$, where $(\mathrm{P}<0.05)$. Conclusion: The combined effect of Maitland spinal mobilization and intermittent mechanical lumbar traction on pain intensity, lumbar ROM, 
and functional disability in patients with chronic nonspecific low back pain is more effective than one of them alone.

\section{INTRODUCTION}

Low Back Pain (LBP) is that the commonest musculoskeletal disorder that affects many of people during their lifetimes [1]. ]. one among the foremost popular mechanical classification is labeling LBP as specific or non-specific [2]. Non-specific low back pain is pain not attributed to a recognizable pathology, not due to a known cause [3], represents $90-95 \%$ of the cases of LBP [4]. For several years, LBP has been both the leading explanation for_days lost from work and the leading indication for medical rehabilitation [5]. The entire direct and indirect costs for the treatment of LBP are estimated to be $\$ 100$ billion annually [6].

There are different methods for LBP treatment like surgery, oral medication, injection at lumbar region, psychotherapy, chiropractic and physiotherapy [7]. Physiotherapy modalities and techniques like electrotherapy, low level laser, ultrasound, massage, shortwave, traction, superficial hat, spinal manipulation and exercise therapy wont to treat such cases [8].

Maitland mobilization technique are thought to profit patients with lumbar mechanical pain through the stimulation of joint mechanoreceptors. These receptors are believed to change the pain-spasm cycle through the presynaptic inhibition of nociceptive fibers in associated structures and therefore the inhibition of the hypertonic muscles, which ultimately improve functional abilities [9].

Posterior-to-anterior (PA) mobilization technique is a sort of Maitland vertebral mobilization applied in Maitland's grading technique[10]. The United Kingdom evidence report on the effectiveness of Manual Therapies reviewed the literature and concluded that spinal manipulation and mobilization has top quality positive evidence supporting its utilization in the treatment of chronic low back pain [11].

There's moderate-quality evidence that manipulation and mobilization are likely to decrease back pain and improve function for patients with chronic low back pain. Multimodal programs could also be a promising option [12]. Lumbar traction is a commonly used method to treat patients with LBP with or without sciatica. Many clinicians also report the use of traction for patients with low back and leg pain [13]._within the United Kingdom and therefore the United States, lumbar traction is utilized by 41 and $77 \%$ of outpatient rehabilitation providers respectively [14].

Variety of RCTs suggest that traction are often an efficient intervention within the management of patients with LBP $[\mathbf{1 5}, \mathbf{1 6}, \mathbf{1 7}]$. There are many theories that describe how traction relieve low back pain, one among them is that ligaments can become contracted or shortened from injury or posture problems, so traction encourages adaptive changes in 
ligaments length and strength and another theory suppose that traction activates the gating mechanism via proprioceptive fibers in ligaments [18].

In order to improve the functional status and quality of life in patients with chronic non-specific low back pain(CNSLBP), it's important to understand which modalities are capable of reducing pain and disability. Therefore, the present study aimed to investigate the combined effects of mechanical traction with Maitland mobilization on pain intensity, ROM, and functional disability in patients with CNSLBP. We hypothesized that patients with CNSLBP who received mechanical traction combined with Maitland mobilization would demonstrate greater reductions in pain, ROM, and functional disability compared to patients who received mechanical traction alone or Maitland mobilization alone.

\section{METHODS}

This randomized controlled trial was conducted to investigate the effects of lumbar mechanical traction, posterior-anterior spinal mobilization and their combined effect in treatment of patients with CNSLBP. It had conducted in outpatient clinic of Sohag hospital. The study protocol was approved by Research Ethical Committee of Faculty of Physical Therapy, Cairo university, Egypt (NO: P. T. REC/012/002181).

\section{Participants}

Sample size calculation was performed prior to the study after doing a pilot study using G*POWER statistical software and revealed that the acceptable sample size for this study was $\mathrm{N}=44$. Forty-four patients $(21$ females and 23 males) participated during this study, diagnosed by their Physicians and referred as patient with CNSLBP. Their ages ranged from 20 to 30 years. They received verbal and written explanation for this study. If they decided to participate during this study, they signed the consent form (Appendix I) which accepted by the Faculty of Physical Therapy. Consenting subjects were assigned randomly into four groups of equal numbers. The randomization performed using a randomization table created by a computer software program., they were randomly allocated into 4 equal groups (each contains 11 patient and receive 3 sessions per week for one 4 weeks).

Group (A): received central posterior-anterior mobilization in addition to conventional physical therapy and advices. Group (B): received intermittent mechanical lumbar traction in addition to conventional physical therapy and advices. Group $(\mathrm{C})$ : received intermittent mechanical lumbar traction with central posterior-anterior mobilization in addition to conventional physical therapy and advices. Group (D) (Control group): received conventional physical therapy (Transcutaneous electrical nerve stimulation, Infrared, and Isometric exercise) and advices.

Inclusion criteria: The patients were male and female with age ranged from 20 to 30 years old with body mass index less than 30 , diagnosed by 
Physician as patient with CNSLBP, back pain with duration of a minimum of three months ago, Conscious and ambulant patient and Pain is evenly distributed to both sides of the body with Protective muscle spasm.

Exclusion criteria: patients with a history of diabetes, any back surgery or deformity of the spine, pregnant woman, unconscious patients or inability to be ambulant, patients with pain less than 3 months, history of epilepsy, Piriformis syndrome, Leg length discrepancy, or cognitive impairment.

\section{Outcome Measures}

\section{Visual analogue scale (VAS)}

VAS is that the commonest feasible tool for the subjective assessment of pain. It is a valid and reliable tool within the assessment of pain intensity [19]. A 10-cm scale was marked with " 0 " (no pain) to "10" (worst imaginable pain), and therefore the subjects were instructed to put a vertical mark on the point indicate his/her pain [20].

\section{Bubble Inclinometer}

It's a non-invasive instrument utilized to measure lumbar range of motion that has good reliability and criterion validity [21]. The Inclinometer was calibrated before the study. Two landmarks were set at lumbar spine as described by Waddell et al [22]. While the patient standing in an upright position; first landmark was located between posterior superior iliac spines at (S1vertebra) and therefore the other one at spinous process of the 12 thoracic vertebrae (T12) on bare skin. Center the inclinometer and zero over the palpated land mark S1 together with your finger by spinning the dial every measure. Have the patient flex forward as far as possible, note the reading at $\mathrm{S} 1$. The patient asked to back to upright position and repeat measurement of flexion at T12. The difference between the reading at S1 and $\mathrm{T} 12$ is true lumbar flexion. Repeat flexion protocol for extension having the patient to extend back to full extension instead flexion and record the value of true extension.

\section{Arabic version of Modified Oswestry disability questionnaire (MODQ) (appendix II)}

The functional level was assessed employing a self- reported validated Arabic version of the ODI [23]. MODQ is a condition-specific outcome measure that helps quantify disability and measure the result of the treatment received for low back pain in patients with low back pain. It is a 10-item questionnaire, with 6 responses to every item numbered from zero to five. The entire is calculated through multiplying the sum of the scores by 2, giving a range of 0 to 100; a higher score reflects higher disability. These items include pain intensity, personal care, lifting, walking, sitting, sleeping, sex life (if applicable), and social life. The first version of the ODI has been revised since its original development and since of the low response rate to items asking about gender, authors made this modification on the first questionnaire. They 
replaced the gender item with an item describing employment and homemaking and was translated into many languages [24, 25].

\section{Intervention procedures}

All participants were treated by the same physiotherapist.

\section{Conventional physical therapy}

\section{a. Infrared}

Superficial heating (infrared lamp), for 20min/session at distance of $60 \mathrm{~cm}$ of the lumbar region, while patient in prone lying position, every other day, for 4 weeks [26].

\section{b. Transcutaneous electrical nerve stimulation}

Transcutaneous electrical nerve stimulation(TENS) is a non-invasive therapeutic modality. TENS units stimulate peripheral nerves via skin surface electrodes at well-tolerated intensities and are capable of being selfadministered [27]. The parameters are: $10 \mathrm{~Hz}, 200 \mathrm{Microsec}, 30 \mathrm{~min}$, electrodes were positioned paraspinal at levels of L4-L5 and L5-S1. The treatment was applied once a day, 3 times per week, day after day, for 4 weeks [28].

\section{c. Isometric exercises for back and abdomen}

Exercise has been considered one among the foremost evidence-based modalities [29]. exercise programs supported a behavior-therapeutic approach to improve physical functional ability, activate the deep muscles and speed up the return to work [30]. From crock lying position, the patient is instructed to contract his abdomen as he is flexing the trunk, within the limits of pain with hold for $15 \mathrm{sec}$. the exercise is performed five timeslsession, with hold for six sec with one minute rest between each repetition then the patient is instructed to do the same with extension with contracting the lower back muscles as he press the lumbar spine down [31].

\section{Posterior- anterior mobilization}

A Passive accessory intervertebral movement (PAIVM) is a mobilization technique that produces movement of a mobile vertebral segment without active participation of muscles associated with the movement [32,33]. The appliance of central posterior-anterior (PA) mobilizations of the lumbar spine as a type of Maitland mobilization is achieved by applying a force on to a vertebral segment in a posterioranterior direction (Back to front). The patient's position for the mobilization intervention was prone on a treatment table with their hands beside and Position of therapist is standing on side of patient placing their pisiform/ulnar surface of hand over the chosen spinous process (SP) with their wrist fully extension. Other hand placed on top of hand to reinforce. Therapist's shoulders should be directly above the SP with elbows slightly bent $[32,33]$.

The therapist uses their weight to apply a PA force to the chosen SP by leaning their body over their arms and performing rocking movements to 
supply oscillatory movements of the vertebra. The direction of mobilization was posterior-anterior. Grade I and II joint oscillations for 30 seconds each with frequency three bouts of 30 oscillations. Grade I joint mobilizations were administered consecutively to the three spinous processes that surround the painful area with 30 seconds of rest in between, followed by grade II joint mobilizations $[\mathbf{3 4 , 3 5 ]}$.

\section{Intermittent mechanical traction}

Mechanical Traction is a non-surgical treatment directed to relieving pressure on structures which will be the main source of pain [36]. The patient position is supine with the hips and knees flexed on the traction table. Therapist tighten any slack within the harness which will have occurred during positioning. Therapist fit the acceptable traction harness on the patient and attach the accessory Clip to the connection point of the traction harness. The therapist Push and hold the Rope Release Button on the touch screen and slowly pull the end of the Traction Cord out from the traction unit.

Traction is applied through the (Tru-Trac) traction unit digital touch screen. Traction force was decided by $40-50 \%$ of subject's body weight, Treatment duration is $20 \mathrm{~min}$ with 30 second hold and $10 \mathrm{sec}$ relax intermittent approach. For those subjects who couldn't tolerate the regime above, the traction force was reduced according to his/her tolerance [37].

\section{Advices}

All groups were received the advices orally and written in paper. Advices are about lifting, standing, sitting, sleeping and exercising, so limiting the foremost confounding factors that may aggravate low back pain, and this maintained the results of follow up accurate the maximum amount as possible [38].

\section{Statistical analysis}

Statistical analysis was conducted using SPSS version 22 (SPSS, Inc., Chicago, IL). data were screened for assumption of normality using the Shapiro-Wilk method which indicated that the data were normally distributed and didn't contravene the parametric presumption. one-way ANOVA tests were used to make sure that there was no statistically significant difference between subjects regarding the base line characteristics. Repeated univariate measurements and multivariate ANOVA were used to compare the chosen parameters for different test groups and measuring times. The significance level was set at $\mathrm{p} \leq 0.05$.

\section{RESULTS}

Data analysis revealed no significant differences between groups regarding the base line characteristics where $(P>0.05)$, as demonstrated in Table 1.With regard to the selected parameters; VAS, Lumbar flexion ROM, Lumbar extension ROM, and MODQ, between-group differences were noteworthy where $(P>0.009)$. Analysis within groups showed a 
considerable difference within the three groups after 4 weeks of intervention compared to the baseline where $(P<0.0001)$. however, pairwise comparisons analysis favored group $\mathrm{C}$, where $(P>0.04)$. Results are illustrated in Table 1,2.

Table 1. Basic characteristics of participants.

\begin{tabular}{|c|c|c|c|c|c|c|c|}
\hline & Group A & Group B & Group C & Group D & $\begin{array}{c}\mathbf{F} \\
\text { value }\end{array}$ & $\begin{array}{c}P \\
\text { value }\end{array}$ & Sig. \\
\hline $\begin{array}{c}\text { Age } \\
\text { (years) }\end{array}$ & $25.91 \pm 3.21$ & $26.18 \pm 2.75$ & $24.82 \pm 2.96$ & $25.27 \pm 2.94$ & 0.475 & 0.702 & NS \\
\hline $\begin{array}{c}\text { BMI } \\
\left(\mathrm{KG} / \mathrm{m}^{2}\right)\end{array}$ & $25.08 \pm 1.34$ & $25.61 \pm 1.85$ & $25.66 \pm 2.24$ & $25.51 \pm 2.22$ & 0.202 & 0.895 & NS \\
\hline Male & 6 & 6 & 6 & 5 & \multirow{2}{*}{0.273} & \multirow{2}{*}{0.965} & \\
\hline Female & 5 & 5 & 5 & 6 & & & \\
\hline
\end{tabular}

SD, standard deviation; p-value, level of significance; BMI, Body mass index

Table 2. Mean VAS, lumbar flexion, lumbar extension and MODQ pre and post treatment of group $A, B, C$ and $D$ :

\begin{tabular}{|c|c|c|c|c|c|c|}
\hline & Group A & Group B & Group C & Group D & $\mathbf{F}$ & Sig \\
\hline Pre-VAS & $4.64 \pm 0.92$ & $4.73 \pm 1.01$ & $4.73 \pm 0.79$ & $4.73 \pm 0.9$ & 0.027 & 0.994 \\
\hline Post-VAS & $2.64 \pm 0.81$ & $2.55 \pm 0.69$ & $1.55 \pm 0.52$ & $3.18 \pm 0.87$ & 9.454 & 0.000 \\
\hline Change & DE-43.1\% & DE-46.09\% & DE-67.23\% & DE-32.77\% & & \\
\hline Pre-LF & $44.45 \pm 5.52$ & $44.36 \pm 5.24$ & $44.91 \pm 4.83$ & $44.82 \pm 5.51$ & 0.028 & 0.993 \\
\hline Post-LF & $49.36 \pm 5.7$ & $49.36 \pm 3.93$ & $55 \pm 3.87$ & $48.45 \pm 5.22$ & 4.392 & 0.009 \\
\hline Change & IN11.05\% & IN11.27\% & IN22.47\% & IN8.1\% & & \\
\hline Pre-LE & $5.18 \pm 2.32$ & $5.36 \pm 2.11$ & $5 \pm 2.24$ & $4.91 \pm 2.88$ & 0.077 & 0.972 \\
\hline Post-LE & $9.27 \pm 3.1$ & $9.09 \pm 2.02$ & $13.18 \pm 2.52$ & $7.73 \pm 3.26$ & 7.891 & 0.000 \\
\hline Change & IN78.96\% & IN69.59\% & IN163.6\% & IN57.43\% & & \\
\hline Pre-MODQ & $34.36 \pm 5.5$ & $33.09 \pm 4.76$ & $34 \pm 4.65$ & $34.18 \pm 5.55$ & 0.134 & 0.940 \\
\hline Post-MODQ & $23.45 \pm 3.59$ & $21.82 \pm 2.6$ & $14.55 \pm 4.01$ & $24.55 \pm 4.11$ & 16.985 & 0.000 \\
\hline Change & DE-31.75\% & DE-34.06\% & DE-57.21\% & DE-28.17\% & & \\
\hline
\end{tabular}

SD, Standard deviation; MD, Mean difference; p-value, Level of significance; VAS, Visual analogue scale; LF, Lumbar flexion; LE, Lumbar extension; MODQ, Modified Oswestry disability questionnaire.

\section{DISCUSSION}

The findings of this study revealed that the combined treatment of intermittent mechanical lumbar traction and central posterior-anterior mobilization showed more significant improvement in pain intensity, ROM, and functional disability, in comparison to patients who received mechanical traction alone or Maitland mobilization alone.

Regarding PA mobilization results, a trial accept as true with the present study, was conducted to research the immediate effect of posterioranterior mobilization on back pain and thus the associated biomechanical changes within the lumbar spine. The posterior-anterior mobilization was found to cause immediate desirable effects in reducing spinal stiffness and therefore the magnitude of back pain. The restoration of the mechanical properties of the spine might be a possible mechanism that explains the 
decrease in pain after manual therapy [39]. On contrary, StamosPapastamos et al., conducted a study to research the effects of lumbar rotational manipulation and lumbar central posterior-anterior mobilization on lumbar bending stiffness and flexion and extension ROM, and concluded that manipulation had no significant effect on bending stiffness or flexion and extension ROM [40]. This discrepancy in findings could even be attributed to the high variability in subjects' characteristics and therefore the assessment methods wont to evaluate lumbar stiffness.

Another study partially agrees with our findings, Abe et al. [41] analyze the posterior chain's flexibility, low back's mobility, trunk extensor's endurance and low back extensors' muscle strength after performed one treatment session using the Maitland method on youth with low back pain. All volunteers were evaluated consistent their perception of pain, flexibility, mobility, muscular strength and muscular endurance. The authors concluded that lumbar PA mobilization was effective for increasing muscular strength and endurance, with stabilization of the level of pain, flexibility and mobility.

Lumbar traction is a traditional treatment modality for CLBP in many countries. few randomized controlled trials proving its effectiveness and utility. Tadano et al. [42] conducted study that was planned as a preparatory experiment for a randomized clinical trial, going to examine the biomechanical change at the lumbar area under lumbar traction and ensure its reproducibility and accuracy as a mechanical intervention, and to reconfirm the clinical impression of the immediate effect of lumbar traction. The authors concluded that lumbar traction can provide a distractive force at the lumbar spine, and patients who experience the appliance of such force show an instant response after traction.

Regarding traction results, Santos et al. [43] conducted study that came in line with our findings aimed to compare the effect of mechanical lumbar traction with low (10\% of body weight) and high traction force (50\% of body weight) on the separation of the vertebrae in vivo using stature variations as criterion. Stature was assessed before and immediately after the traction and each five minutes for half-hour after traction ceased. Immediately after the traction both protocols induced a significant increase in stature, however the magnitude of the increase was significantly related to the traction with $50 \%$ of body weight.

Another study supports our findings where it compared the effects of high-force versus low-force lumbar traction within the treatment of acute lumbar sciatica secondary to disc herniation. A randomized double-blind trial was performed, and 17 subjects with acute lumbar sciatica secondary to disc herniation were assigned to high-force traction at $50 \%$ body weight or low force traction at $10 \%$ body weight for 10 sessions in 2 weeks. Radicular pain, lumbo-pelvic-hip complex motion, lumbar-spine mobility, nerve root 
compression, disability, drug consumption, and overall evaluation of each patient were measured at days $0,7,1,4$, and 28 . For this preliminary study, patients with acute lumbar sciatica secondary to disc herniation who received 2 weeks of lumbar traction reported reduced radicular pain and functional impairment and improved well-being no matter of the traction force group to which they were assigned. The effects of the traction treatment were independent of the initial level of medication and seemed to be maintained at the 2-week follow-up [44].

Regarding the combined group findings, it was supported by a recent study that conducted to determine the consequences of motorized spinal decompression combined with spinal mobilization also as lumbar stabilization exercises on patients with discogenic low back pain (LBP). A complete of 30 adults with discogenic LBP volunteered to participate during this study. The whole treatment consisted of 20 visits over a 4-week period. Comparisons of changes within the Oswestry Disability Index (ODI) and straight leg raise (SLR) test at pre-intervention, after 10 treatment sessions, and at discharge (after 20 treatment sessions) were analyzed. The authors conclude that Spinal decompression treatment combined with spinal mobilization and lumbar stabilization exercises significantly improved the clinical outcome measures of ODI score and SLR test in patients with LBP secondary to intervertebral disc herniation [45].

The limitations of this research are worth mentioning; absence of blinding, where all participants were evaluated by the same investigators who implemented the intervention. Additionally, there aren't any follow-up data on the participants' clinical status, which might help us monitor the long-term effects of our intervention.

\section{CONCLUSION}

The combined effect of Maitland spinal mobilization and intermittent mechanical lumbar traction on pain intensity, lumbar ROM, and functional disability in patients with chronic nonspecific low back pain is more effective than one of them alone.

\section{Acknowledgements}

Firstly, I would like to express foremost sincere thanks to ALLAH for these great blessings to finish this study. Then, I would like to express my sincere gratitude to all the patients who participated in this study and each person for their direct or indirect help for providing us with the privilege to complete this study without them this work wouldn't be possible.

\section{Declaration of Conflicting Interests}

The author(s) declared no potential conflicts of interest with respect to the research, authorship, and/or publication of this article. 


\section{Funding}

The author(s) received no financial support for the research, authorship and/or publication of this article.

\section{REFERENCE}

[1]. Papageorgiou, A.C. ; P.R. Croft ; S. Ferry ; M.I. Jayson and A.J. Silman (1995): Estimating the prevalence of low back pain in the general population. Evidence from the South Manchester Back Pain Survey. Spine.; 20(17):1889-94.

[2]. O'Sullivan, P. (2005):Diagnosis and classification of chronic low back pain disorders: maladaptive movement and motor control impairments as underlying mechanism. Manual Therapy.; 10(4):242-55.

[3]. Maher, C. ; Underwood M. and R.Buchbinder (2017). Musculoskeletal Division, The George Institute for Global Health, Sydney Medical School, University of Sydney.

[4]. Bardin, L. D. ; P. King and C. G. Maher (2017). Diagnostic triage for low back pain: a practical approach for primary care. Medical Journal of Australia, 206(6): 268-273.

[5]. Marschall, J. ; H.D. Nolting ; S. Hildebrandt-Heene and H. Sydow (2016). Gesundheitsreport 2016: analyse Der Arbeitsunfähigkeitsdaten. Schwerpunkt: Gender und Gesundheit. DAK-Gesundheit.

[6]. Laroche, F. and S. Perrot (2013). Managing Sciatica and Radicular Pain in Primary Care Practice, Springer Healthcare Limited.

[7] Wippert P.M. ; J. de Witt Huberts ; K. Klipker ; S. Gantz ; M. Schiltenwolf and F. Mayer (2015): Beschreibung und empirische fundierung des verhaltenstherapeutischen moduls der MiSpEx-intervention. Der Schmerz. ;29:658-663.

[8]. Roger Chou, M.D. and M.S. Laurie Hoyt Huffman (2007) Nonpharmacologic Therapies for Acute and Chronic Low Back Pain: A Review of the Evidence for an American Pain Society/American College of Physicians Clinical Practice Guideline. Ann Intern Med.;147: 492-504

[9]. Hisham Mohamed Hussien ; Neveen Abdellatif Abdel-Raoof ; Omaima Mohamed Kattabei and Hassan Hussien Ahmed (2017). Effect of Mulligan Concept Lumbar SNAG on Chronic Nonspecific Low Back Pain, Journal of Chiropractic Medicine 16(2): 94-102.

[10]. Hengeveld, E. and K. Banks (2013). Maitland's Peripheral Manipulation E-Book: Management of Neuromusculoskeletal Disorders, Elsevier Health Sciences. 
[11]. Bronfort, G. et al., (2010). Bronfort G, Haas M, Evans R, Leininger B, Triano J, Effect of manual therapies: The UK evidence report Chiropractic and Osteopathy.

[12]. Ian D. Coulter ; Cindy Crawford ; Eric L. Hurwitz ; Howard Vernon ; Raheleh Khorsan ; Marika Suttorp Booth and Patricia M. Herman (2018):Manipulation and mobilization for treating chronic low back pain: a systematic review and metaanalysis. Spine J. , 18(5): 866-879.

[13]. Harte, A.A. ; J.H. Gracey and G.D. Baxter (2005) Current use of lumbar traction in the management of low back pain: results of a survey of physiotherapists in the United Kingdom. Arch Phys Med Rehabil.;86(6):1164-9

[14]. Madson, T.J. and J.H. Hollman (2015). Lumbar traction for managing low back pain: a survey of physical therapists in the United States. J Orthop Sports Phys Ther.;45(8):586-95.

[15]. Fritz, J.M. ; W. Lindsay ; J.W. Matheson ; G.P. Brennan ; S.J. Hunter ; S.D. Moffit and et al. (2007). Is there a subgroup of patients with low back pain likely to benefit from mechanical traction? results of a randomized clinical trial and subgrouping analysis. Spine.;32(26):E793-800.

[16]. Prasad, K.M. ; B.A. Gregson ; G. Hargreaves ; T. Byrnes ; P. Winburn and A.D. Mendelow (2012). Inversion therapy in patients with pure single level lumbar discogenic disease: a pilot randomized trial. Disabil Rehabil.;34(17):1473-80

[17]. Diab, A.A.M. and I.M. Moustafa (2013). The efficacy of lumbar extension traction for sagittal alignment in mechanical low back pain: a randomized trial. J Back Musculoskelet Rehabil.; 26(2): 213-20.

[18]. Chung, T.-S., H.-E. Yang, S. J. Ahn and J. H. Park (2015). "Herniated lumbar disks: real-time MR imaging evaluation during continuous traction." Radiology., 275(3): 755-762.

[19]. Clark, P. ; P. Lavielle and H. Martínez (2003). Learning from pain scales: patient perspective. J Rheumatol.;30:1584-1588

[20]. Bird, S.B. and E.W. Dickson (2001). Clinically significant changes in pain along the visual analog scale. Ann Emerg Med.;38:639-643.

[21]. Morey J Kolber ; Matias Pizzini ; Ashley Robinson ; Dania Yanez and William J. Hanney (2013): The Reliability And Concurrent Validity of Measurements used to Quantify Lumbar Spine Mobility: An Analysis of an Iphone ${ }^{\circledR}$ Application and Gravity Based Inclinometry. Int J Sports Phys Ther., 8(2): 129-137. 
[22]. Waddell, G. ; D. Somerville ; I. Henderson and M. Newton (1992): Objective clinical evaluation of physical impairment in chronic low back pain. Spine;17: 617-628.

[23]. M. Guermazi ; M. Mezghani ; S. Ghroubi ; M. Elleuch ; A. Ould Sidi Med ; S. Poiraudeau ; F. Mrabet ; J. Dammak ; J. Fermanian ; S. Baklouti ; S. Sellami ; M. Revel and M.H. Elleuch (2005). The Oswestry index for low back pain translated into Arabic and validated in a Arab population. Annales de réadaptation et de médecine physique, 48: 1-10

[24]. Fritz, J. M. and J. J. Irrgang (2001). "A comparison of a modified Oswestry low back pain disability questionnaire and the Quebec back pain disability scale." Physical therapy, 81(2): 776-788.

[25]. Smeets, R. ; A. Köke ; C. W. Lin ; M. Ferreira and C. Demoulin (2011). "Measures of function in low back pain/disorders: Low Back Pain Rating Scale (LBPRS), Oswestry Disability Index (ODI), Progressive Isoinertial Lifting Evaluation (PILE), Quebec Back Pain Disability Scale (QBPDS), and RolandMorris Disability Questionnaire (RDQ)." Arthritis care \& research 63(S11).

[26]. Torad, A. A. ; M. Mostafa ; A. Saleh ; A. Genedy and M. Torad (2015). "Laser Acupuncture versus ultrasound in treatment of discogenic sciatica."International Journal of International journal of Research and Review in Health Sciences Recent Advances in Multidisciplinary Research,2(2): 0226-0231.

[27]. Khadilkar, A. ; S. Milne ; L. Brosseau ; V. Robinson ; M. Saginur ; B. Shea ; P. Tugwell and G. Wells (2005). Transcutaneous electrical nerve stimulation (TENS) for chronic low-back pain. Cochrane Database Syst Rev:CD003008

[28]. Quittan, M. ; W. Bily ; R. Crevenna ; V. Fialka-Moser ; W. Grestenberger ; C. Hofer ; P. Husslein ; H. Kern ; R. Kondo and C. Lampl (2016). "Transcutaneous Electrical Nerve Stimulation (TENS) in Patients with Pregnancy-Induced Low Back Pain and/or Pelvic Girdle Pain." Physikalische Medizin, Rehabilitationsmedizin, Kurortmedizin., 26(02): 91-95.

[29]. Wolsko, P.M. ; D.M. Eisenberg; R.B. Davis; R. Kessler and Phillips R.S. (2003): Patterns and perceptions of care for treatment of back and neck pain: results of a national survey. Spine (Phila Pa 1976). 2003; 28:292-297; discussion 298. http://dx.doi. org/10.1097/01.BRS.0000042225.88095.7C

[30]. Oesch, P. ; J. Kool ; K.B. Hagen and S. Bachmann (2010): Effectiveness of exercise on work disability in patients with non-acute non-specific low back pain: systematic review and 
meta-analysis of randomised controlled trials. J Rehabil Med., 42: 193-205.

[31]. McGill, S. M. ; A. Childs and C. Liebenson (1999). "Endurance times for low back stabilization exercises: clinical targets for testing and training from a normal database." Archives of Physical Medicine and Rehabilitation., 80(8): 941-944.

[32]. Hengeveld, E. and K. Banks (2013). Maitland's Peripheral Manipulation E-Book: Management of Neuromusculoskeletal Disorders, Elsevier Health Sciences.

[33]. Edmond, S. L. (2016). Joint Mobilization/Manipulation - E-Book: Extremity and Spinal Techniques, Elsevier Health Sciences.

[34]. Pallavi Chopade, (2018), Comparison of Maitland's mobilisation and Mckenzie therapy in patients with nonspecific low back pain

[35]. Ghai, S. and I. Ghai (2014). Role of various mobilization maneuvers in the management of low back pain. Research \& Reviews in Bio Sciences, 8(10): 374-381.

[36]. Pellecchia, G. L. (1994). "Lumbar traction: a review of the literature." Journal of Orthopaedic \& Sports Physical Therapy 20(5): 262-267.

[37]. Judovich, B. D. (1955). Lumbar traction therapy-elimination of physical factors that prevent lumbar stretch. Journal of the American Medical Association, 159(6): 549-550.

[38]. Koes, B. (2010). "Moderate quality evidence that compared to advice to rest in bed, advice to remain active provides small improvements in pain and functional status in people with acute low back pain." Evidence-based medicine., 15(6): 171-172.

[39]. Gary L. Shum ; Bonnie Y. Tsung and Raymond Y. Lee (2013). "The immediate effect of posteroanterior mobilization on reducing back pain and the stiffness of the lumbar spine." Archives of Physical Medicine and Rehabilitation., 94(4): 673-679.

[40]. Stamos-Papastamos, N., N. J. Petty, J. M. J. J. o. m. Williams and p. therapeutics (2011). "Changes in bending stiffness and lumbar spine range of movement following lumbar mobilization and manipulation." 34(1): 46-53.

[41]. Abe, K. Y. ; B. M. Tozim ; M. T. J. M. T. Navega ; Posturology and R. Journal (2015). "Acute effects of Maitland's central posteroanterior mobilization on youth with low back pain." MTP \& Rehab Journal.,13(234): 1-5.

[42]. Tadano, S. ; H. Tanabe ; S. Arai ; K. Fujino ; T. Doi and M.J.B. M.D. Akai (2019). "Lumbar mechanical traction: a biomechanical assessment of change at the lumbar spine." 20(1): 155 . 
[43]. Santos, S. and F. Ribeiro (2011). Acute effects of mechanical lumbar traction with different intensities on stature. Acta Reumatologica Portuguesa, 36(1): 38-43.

[44]. Isner-Horobeti, M.E. ; S.P. Dufour ; M. Schaeffer ; E. Sauleau ; P. Vautravers ; J. Lecocq ; A.J.J.O.M. Dupeyron and P. Therapeutics (2016). "High-force versus low-force lumbar traction in acute lumbar sciatica due to disc herniation: a preliminary randomized trial." 39(9): 645-654.

[45] Lee, Y. ; C.R. Lee and M. Cho (2012). "Effect of decompression therapy combined with joint mobilization on patients with lumbar herniated nucleus pulposus." Journal of Physical Therapy Science., 24(9): 829-832.

$$
\begin{aligned}
& \text { تأثير تحريك ميتلاند للعمود الفقري مع الثد الميكانيكي للفقرات القطنية على :829 } \\
& \text { المرضى اللاذين يعانون من ألام أسفل الظهر الغير محددة }
\end{aligned}
$$

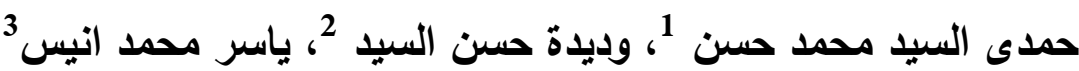

$$
\begin{aligned}
& \text { 1أخصائي علاج طبيعي لدي وزارة الصحة بمديرية الصحة سوهاج. } \\
& \text { 2/استاذ العلاج الطبيعي بقسم العلوم الاساسية، كلية العلاج الطييعي، جامعة القاهرة. }
\end{aligned}
$$

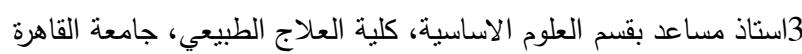

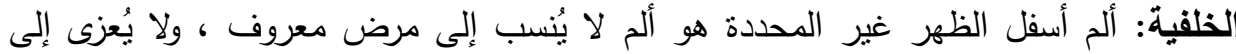

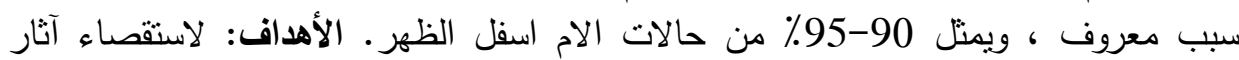

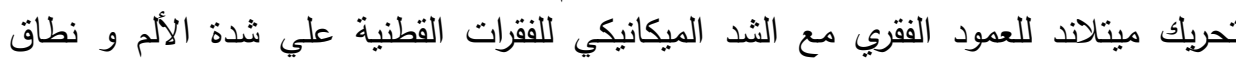

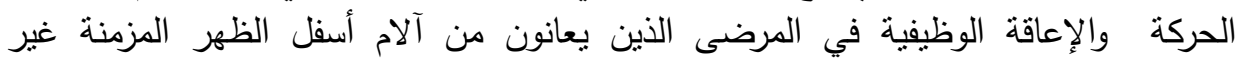

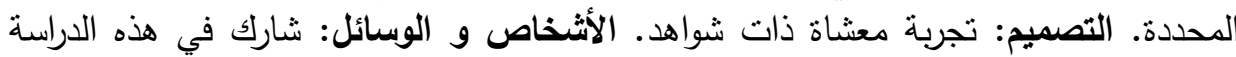

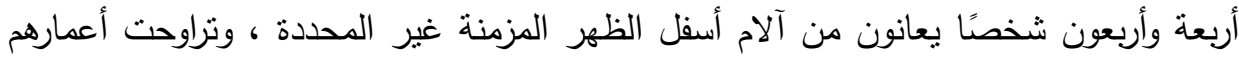

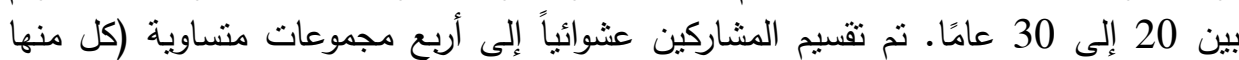

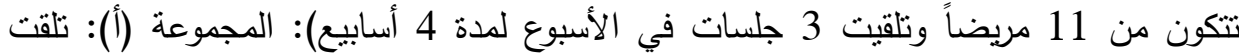

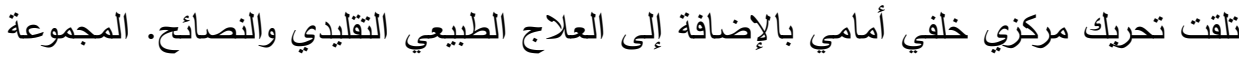

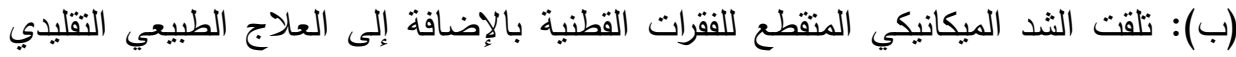

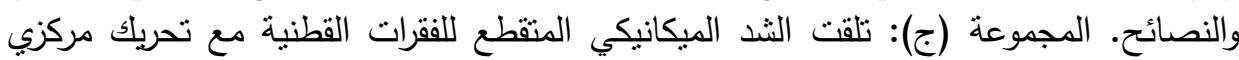

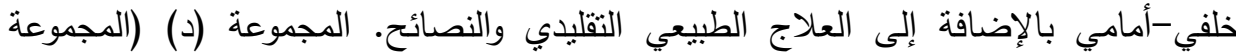

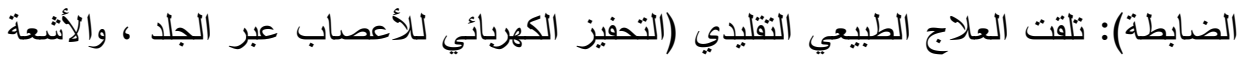

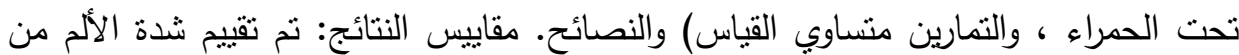
خلال المقياس التتاظري البصري، المعدل الحركي لاسفل الظهر التي تم تقييمها بواسطة مقياس

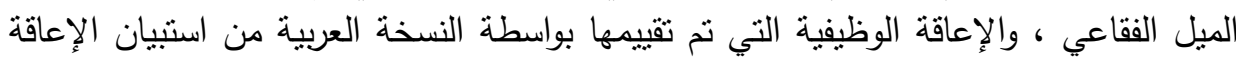

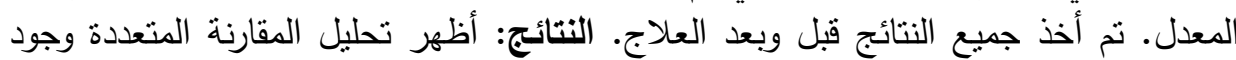


فرق محتمل بين المجموعات من حيث المعايير المختارة ، بينما فضلت التغييرات الرئيسية

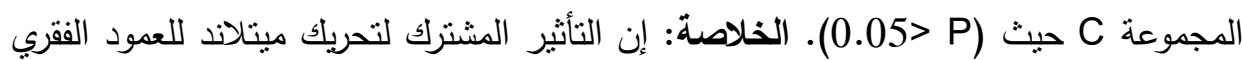
والثد القطني الميكانيكي المنقطع على شدة الألم ، و معدل الحركة للفقرات القطنية ، والإعاقة القاقة

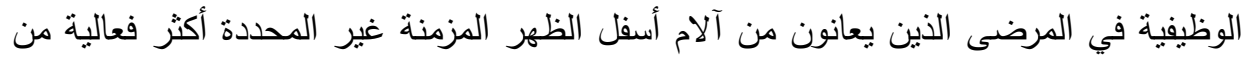

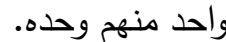
الكلمات الأساسية: تحريك ميتلاند للعمود الفقري؛ الثند الميكانيكي القطني ، الثأثثر المشترك، آلام أسفل الظهر غينان لاعبرد محددة. 